\title{
Risk Factors of Pancreatic Carcinoma in Rural Area: Case Control Study $\underline{(\text { Original Article) }}$
}

\author{
Authors \\ Avinash Gurujala ${ }^{1}$, Santosh Kumar M.B.S.C ${ }^{2}$ \\ ${ }^{1}$ Post Graduate, Final Year Department of General Surgery, M.N.R Medical College and Hospital, \\ Sangareddy, Telangana PIN - 502001 \\ Email: dravinash2011@gmail.com,Mob - +918019548838 \\ ${ }^{2}$ Assistant Professor, Department of General Surgery, M.N.R Medical College and Hospital, \\ Sangareddy, Telangana, PIN - 502001 \\ Email: santoshmashetty1984@gmail.com, Mob - +919849852716
}

\begin{abstract}
The risk factors of pancreatic carcinoma was poorly understand, especially in our country as there were no proper studies done in our country. The main purpose of this study to know the risk factors of pancreatic carcinoma in rural India.

OBJECTIVES - There are many well established risk factors for pancreatic carcinoma like chronic pancreatitis, diabetes mellitus, tobacco smoking and alcohol consumption. We have studied the independent effects of these multiple risk factors for pancreatic carcinoma.

METHODS - We conducted a case control study involving 40 patients with clinically diagnosed pancreatic carcinoma and 40 frequency matched controls.

RESULTS - Chronic pancreatitis, diabetes mellitus, tobacco smoking and alcohol consumption were significant risk factors for the pancreatic carcinoma. Approximately 42.5\%, 62.5\%, 60\%, 55\% of pancreatic carcinoma patients in this study were belong to chronic pancreatitis, diabetes mellitus, smoking and alcohol respectively. The risk of developing pancreatic carcinoma in chronic pancreatitis, diabetes mellitus, tobacco smoking was 5, 3.5, 5, and 5 respectively. By multivariate analysis of binary logistic regression chronic pancreatitis and diabetes mellitus were found to be the risk factors of pancreatic carcinoma.

CONCLUSIONS - chronic pancreatitis, diabetes mellitus, tobacco smoking and alcohol consumption ( $>60 \mathrm{ml}$ ethanol/day) are proven to be the most established risk factors for pancreatic carcinoma.

Keywords-Pancreatic carcinoma, Risk factors, Chronic Pancreatitis, Diabetes Mellitus, Alcohol, Tobacco Smoking
\end{abstract}

\section{INTRODUCTION}

Pancreatic carcinoma remains a very fatal disease regardless of advances in the surgical techniques, care of the patient, the documented advantage of adjuvant therapy and the evolvement of multidisciplinary care. In developed countries, pancreatic cancer is the fifth leading cause of cancer-related deaths after lung, stomach, colorectal, and breast cancers $^{(1)}$. In the United States, there were an estimated 42,470 new cases of pancreatic cancer in 2009 with approximately 35,240 deaths, the fourth most common cause of 
cancer-related death ${ }^{(2)}$. Of patients with available data in the United States diagnosed with pancreatic cancer in the years 1996 to 2004, less than $10 \%$ presented with local disease, $26 \%$ with regional disease, and over half had distant metastases ${ }^{(2)}$. Thus, the management of pancreatic carcinoma still a challenge to medical community.

The causes of pancreatic carcinoma was not well established, but the prior studies have indicated that cigarette smoking, diabetes mellitus, chronic pancreatitis, obesity, alcohol consumption, hepatitis b virus infection, family history and genetic disorders were most important risk factors associated with pancreatic carcinoma ${ }^{(3-6)}$. Though pancreatic carcinoma is an aggressive tumour, we do not have any screening programme. So the understanding of risk factors for pancreatic carcinoma is very important. Thus, we can intervene early and improve the survival rate of patients with pancreatic carcinoma. There are very few studies regarding risk factors for pancreatic carcinoma in our country. Hence this study is an effort to know about the risk factors of pancreatic cancer in rural areas.

\section{MATERIALS AND METHODS}

This was a prospective case control study, which was carried out over a period of 1 year (September 2012 to September 2013), in department of general surgery, MNR Medical college and hospital, sangareddy, India. We have taken written informed consent from the patients who are willing to participate in the study. A total of 80 subjects were taken for this study.

Cases were patients with clinically, radiologically and pathologically confirmed diagnosis of pancreatic ductal adenocarcinoma in our hospital. Patients with other than pancreatic adenocarcinoma such as neuroendocrine tumour, adenomas, cysts, or unknown primary tumours.

The control subjects were healthy people and genetically unrelated family members of patients who have admitted for other health problems. We try to match the controls to patients in terms of age and sex. We have interviewed patients and control by following a written protocol and collected the essential information regarding smoking, alcohol, diabetes mellitus and chronic pancreatitis.

Smoking history was taken in pack years. It was calculated by number of years of smoking $\times$ number of packs of cigarettes smoked per day. Heavy alcohol consumption was defined as consumption of $>60 \mathrm{ml}$ of ethanol per day ${ }^{(7)}$. Questionnaire also consists of past medical history like diabetes mellitus, pancreatitis.

STATISTICS- Number allocated in each group $=40$, assuming anticipated odds ratio $=2.4$, power $(1-\beta)=80 \%, \alpha$ (error) $=5$. Chi square test and Multivariate analysis of binary logistic regression were used.

\section{RESULTS}

The results of the analysis of data on 40 patients who were diagnosed to have carcinoma pancreas and treated accordingly as follows

\section{a. Age Distribution}

Table no 1: Age-distribution

\begin{tabular}{|c|c|c|c|c|c|c|}
\hline \multirow[t]{2}{*}{$\begin{array}{l}\text { Age } \\
\text { (Yrs) }\end{array}$} & \multicolumn{2}{|r|}{ Cases } & \multicolumn{2}{|c|}{ Control } & \multicolumn{2}{|r|}{ Total } \\
\hline & $\mathrm{N}$ & $\%$ & $\mathrm{~N}$ & $\%$ & $\mathrm{~N}$ & $\%$ \\
\hline$>60$ & 18 & 45 & 8 & 20 & 13 & 32.5 \\
\hline$<60$ & 22 & 55 & 32 & 80 & 27 & 67.5 \\
\hline Total & 40 & 100 & 40 & 100 & 40 & 100 \\
\hline $\begin{array}{c}\chi^{2} \\
95 \% \mathrm{CI}\end{array}$ & $\begin{array}{l}8, \\
-8.8\end{array}$ & $\mathrm{P}=0.017$ & & & & $\mathrm{R}=3.273$ \\
\hline
\end{tabular}

$\chi^{2}$ - chi square test, $\mathrm{df}$ - degrees of freedom, OR Odds Ratio, CI - Confidence Interval

In this study, majority of patients were <60years $(55 \%)$ age group. In our study, the median age was 58.57. The age of the youngest patient was 40 years old, while the age of oldest patient was 82 years old in our study. 


\section{b. Chronic pancreatitis}

Table no 2: Distribution of Chronic Pancreatitis

\begin{tabular}{|l|l|l|l|l|l|l|}
\hline $\begin{array}{l}\text { Chronic } \\
\text { Pancreatitis }\end{array}$ & \multicolumn{2}{|l|}{ Cases } & \multicolumn{3}{|c|}{ Control } & \multicolumn{2}{|c|}{ Total } \\
\cline { 2 - 8 } & $\mathrm{N}$ & $\%$ & $\mathrm{~N}$ & $\%$ & $\mathrm{~N}$ & $\%$ \\
\hline Yes & 17 & 42.5 & 5 & 12.5 & 22 & 27.5 \\
\hline No & 23 & 57.5 & 35 & 87.5 & 58 & 72.5 \\
\hline Total & 40 & 100 & 40 & 100 & 80 & 100 \\
\hline $\begin{array}{l}\chi^{2}=9.028, \mathrm{df}=1, \quad \mathrm{P}=0.0027 \\
95 \% \mathrm{CI}=1.676-15.975\end{array}$ & (statistically significant), OR=5.174, \\
\hline
\end{tabular}

In this study, $42.5 \%$ of cases with pancreatic carcinoma were found to have chronic pancreatitis as compared to $12.5 \%$ in control group. The patients with chronic pancreatic were 5 times more at risk of developing pancreatic carcinoma than others and this was found to be statistically significant $(\mathrm{p}<0.05)$ (Table no 2).

\section{c. Diabetes Mellitus}

In this study, $62.5 \%$ of cases with pancreatic carcinoma were found to have diabetes mellitus as compared to $30 \%$ in control group. The patients with chronic pancreatitis were 3.5 times more at risk of developing pancreatic carcinoma than others and this was found to be statistically significant $(\mathrm{p}<0.05)$ (Table no3).

Table no 3: Distribution of Diabetes Mellitus

\begin{tabular}{|c|c|c|c|c|c|c|}
\hline \multirow{2}{*}{$\begin{array}{l}\text { Diabetes } \\
\text { Mellitus }\end{array}$} & \multicolumn{2}{|r|}{ Cases } & \multicolumn{2}{|c|}{ Control } & \multicolumn{2}{|r|}{ Total } \\
\hline & $\mathrm{N}$ & $\%$ & $\mathrm{~N}$ & $\%$ & $\mathrm{~N}$ & $\%$ \\
\hline Yes & 25 & 62.5 & 12 & 30 & 37 & 46.3 \\
\hline No & 15 & 37.5 & 28 & 70 & 43 & 53.8 \\
\hline Total & 40 & 100 & 40 & 100 & 80 & 100 \\
\hline $\begin{array}{l}\chi^{2}=7.2 \\
95 \% \mathrm{CI}=1\end{array}$ & & 0.007 & & & nt), & 2 \\
\hline
\end{tabular}

\section{d. Smoking}

In this study, $60 \%$ of cases with pancreatic carcinoma were smokers as compared to $22.5 \%$ in control group. The patients who were smokers were 5 times more at risk of developing pancreatic carcinoma than others and this was found to be statistically significant $(p<0.05)$ (Table no 4).
Table no 4: Distribution of Smoking

\begin{tabular}{|c|c|c|c|c|c|c|}
\hline \multirow[t]{2}{*}{ Smoking } & \multicolumn{2}{|r|}{ Cases } & \multicolumn{2}{|c|}{ Control } & \multicolumn{2}{|r|}{ Total } \\
\hline & $\mathrm{N}$ & $\%$ & $\mathrm{~N}$ & $\%$ & $\mathrm{~N}$ & $\%$ \\
\hline Yes & 24 & 60 & 9 & 22.5 & 33 & 41.3 \\
\hline No & 16 & 40 & 31 & 77.5 & 47 & 58.8 \\
\hline Total & 40 & 100 & 40 & 100 & 80 & 100 \\
\hline $\begin{array}{l}\chi^{2}=11 . \\
95 \% \mathrm{CI}=1\end{array}$ & d & $=0.0007$ & & & nt), & $=5.10$ \\
\hline
\end{tabular}

\section{e. Alcohol}

In this study, $55 \%$ of cases with pancreatic carcinoma were alcoholics as compared to $20 \%$ in control group. The patients who were alcoholics were 5 times more at risk of developing pancreatic carcinoma than others and this was found to be statistically significant $(\mathrm{p}<0.05)($ Table no 5).

Table no 5: Distribution of Alcohol

\begin{tabular}{|l|l|l|l|l|l|l|}
\hline \multirow{2}{*}{ Smoking } & \multicolumn{2}{|l|}{ Cases } & \multicolumn{3}{|r|}{ Control } & \multicolumn{2}{r|}{ Total } \\
\cline { 2 - 7 } & $\mathrm{N}$ & $\%$ & $\mathrm{~N}$ & $\%$ & $\mathrm{~N}$ & $\%$ \\
\hline Yes & 22 & 55 & 8 & 20 & 30 & 37.5 \\
\hline No & 18 & 45 & 32 & 80 & 50 & 62.5 \\
\hline Total & 40 & 100 & 40 & 100 & 80 & 100 \\
\hline $\begin{array}{l}\chi^{2}=10.453, \mathrm{df}=1, \mathrm{P}=0.0012 \text { (statistically significant), OR=4.889, } \\
95 \% \mathrm{CI}=1.809-13.211\end{array}$ &
\end{tabular}

By multivariate analysis of binary logistic regression chronic pancreatitis and diabetes mellitus were found to be the risk factors of pancreatic carcinoma (Table no 6).

Table no 6: Multivariate analysis of risk factors of Pancreatic Carcinoma

\begin{tabular}{|l|l|l|l|l|l|l|}
\hline Variables & B & S.E & Wald & df & Sig. & $\begin{array}{l}\text { Exp } \\
(\mathbf{B})\end{array}$ \\
\hline Age > 60 yrs & .878 & .595 & 2.175 & 1 & .140 & 2.405 \\
\hline $\begin{array}{l}\text { Chronic } \\
\text { pancreatitis }\end{array}$ & 1.455 & .650 & 5.016 & 1 & .025 & 4.283 \\
\hline $\begin{array}{l}\text { Diabetes } \\
\text { Mellitus }\end{array}$ & 1.102 & .549 & 4.031 & 1 & .045 & 3.009 \\
\hline Smoking & .550 & .823 & .447 & 1 & .504 & 1.733 \\
\hline Alcohol & .971 & .836 & 1.350 & 1 & .245 & 2.642 \\
\hline Constant & -3.233 & .837 & 14.918 & 1 & .000 & .039 \\
\hline
\end{tabular}

B - Coefficient for the constant in the null model; Wald and Sig. - Wald chi square test, which will tests the null hypothesis that the constant equals zero; df - degrees of freedom; $\operatorname{EXP}(B)$ exponentiation of the $\mathrm{B}$ coefficient 


\section{DISCUSSION}

Our study is one of the few studies done in India, regarding assessment of multiple risk factors of pancreatic carcinoma simultaneously. In our study, we have confirmed the role of chronic pancreatitis, tobacco smoking, diabetes mellitus and alcohol as risk factors for pancreatic carcinoma. In our study, the average age of incidence is 58 years and the females to male ratio was 1:1.6. In the study conducted by Manal Hassan et al $1.9 \%$ were $<40 \mathrm{yrs}, 11.9 \%$ between $40-50$ years, $29.2 \%$ in the age group of 51-60 years, $35.7 \%$ in the age group of $61-70$ years and $21.3 \%$ in the age group of above 71 years $^{(8)}$.

In our study, $42.5 \%$ of cases with pancreatic carcinoma found to have chronic pancreatitis as compared to control group. There was a chance that pancreatic carcinoma may mimic as chronic pancreatitis due to blockage of pancreatic duct by tumour $^{(9)}$. So to avoid this we have analyzed the subjects separately who had been diagnosed with pancreatitis, at least more than 2years before the diagnosis of pancreatic cancer ${ }^{(8)}$. As we all know the pancreatic carcinoma is an aggressive tumour with overall five year survival rate is $3 \%^{(10)}$. In a study conducted by Lowenfels $\mathrm{AB}$ et al the risk of developing pancreatic carcinoma was a 16.5 fold higher than controls ${ }^{(9)}$. In a study conducted by the Chari ST et al relative risk for pancreatic cancer in patients with TCP was $100 \quad(95 \%$ confidence interval 37 to 218$)^{(11)}$.

In our study, $62.5 \%$ of cases with pancreatic carcinoma were found to have diabetes mellitus as compared to $30 \%$ in control group. In the study conducted by Manal Hassan et al 39.2\% of the cases had diabetes mellitus ${ }^{(8)}$. In the study conducted by Gullo L et al $22.8 \%$ of pancreatic carcinoma patient's had diabetes mellitus ${ }^{12}$. In diabetes, there will be higher levels of glucose in blood, hyperinsulinemia and greater free fatty acids which may cause pancreatic carcinoma ${ }^{(13}$ - 15). In experimental model in hamster, it was proven that islet cell proliferation associated with peripheral insulin resistance may enhance the carcinogenesis of pancreas ${ }^{(16)}$.
Pancreatic tumours can cause diabetes mellitus by increasing peripheral insulin resistance ${ }^{(17)}$, suppressing insulin production and impairing proinsulin conversion ${ }^{(18,19)}$ and causing chronic inflammation $^{(19,20)}$. So it is very difficult to differentiate that diabetes was due to pancreatic carcinoma or pancreatic carcinoma was due to diabetes mellitus as both the theories are supported with evidences. Whatever the reason, it is better to be cautious and consider diabetes mellitus as a risk factor.

Other important risk factor included in our study was alcohol consumption. In this study, $55 \%$ were alcoholics as compared to $20 \%$ in control group. In the study conducted by Manal Hassan et al only $23.6 \%$ were alcoholics ${ }^{(8)}$. It was a well-known fact that chronic alcohol consumption will lead chronic pancreatitis $^{(21)}$, which was a known risk factor for pancreatic carcinoma ${ }^{(9,22)}$. In a study done by Silverman DT et al had shown no relation between regular alcohol drinking and pancreatic carcinoma but there was elevated risk in heavy drinkers ${ }^{(23)}$. $60 \%$ of cases with pancreatic carcinoma in our study were smokers as compared to $22.5 \%$ in control group. Manal Hassan et al study shows $60 \%$ of cases were smokers ${ }^{(8)}$. In a study done by Lowenfels et al, the pancreatic cancer was developed 20 years earlier in smokers among the patients with hereditary pancreatitis ${ }^{(24)}$. Tobacco smoking will cause oxidative stress, which will lead to chronic inflammation, irreversible DNA damage and finally causing pancreatic cancer ${ }^{(24)}$. In a study done by Silverman DT reported that the association between women and smoking was more than men ${ }^{(3)}$.

\section{CONCLUSION}

This is the first study, regarding risk factors for pancreatic carcinoma to be done in rural population of India. Chronic pancreatitis, diabetes mellitus, alcohol and tobacco smoking were found to be risk factors for pancreatic carcinoma. Diabetes mellitus and chronic pancreatitis were definite risk factors as shown by the multivariate linear regression analysis. We have to develop a risk model assessment for 
pancreatic cancer which will aid in the screening and better management of patient.

\section{REFERENCES}

1. Ries LAG, Melbert D, Krapcho M, et al. SEER cancer statisties review 1975-2004; based on November 2006 SEER data submission. World Wide Web URL: http://seer.cancer.gov/csr/1975_2004/.Bethe sda, MD: National Cancer Institute, 2007.

2. Jemal A, Siegel R. Ward E, et al. Cancer statistics,2009. CA Cancer J Clin 2009; 59:225.

3. Silverman DT, Dunn J, Hoover R, et al. Cigarette smoking and pancreas cancer: a case-control study based on direct interviews. J Natl Cancer Inst 1994; 86:1510-1516.

4. Silverman DT, Brown LM, Hoover RN, et al. Alcohol and pancreatic cancer in blacks and whites in the United States. Cancer Res 1995;55:4899-4905.

5. Silverman DT, Swanson CA, Gridley G, et al. Dietary and nutritional factors and pancreatic cancer: a case-control study based on direct interviews. J Natl Cancer Inst 1998;90:1710-1719.

6. Silverman DT, Schiffman M, Everhart J, et al. Diabetes mellitus, other medical conditions and familial history of cancer as risk factors for pancreatic cancer. $\mathrm{Br} \mathrm{J}$ Cancer 1999;80:1830-1837.

7. Diaz LE, Montero A, Gonzalez-Gross M, et al. Influence of alcohol consumption on immunological status: A review, Eur J Clin Nutr 2002;56(suppl 3):s50-3.

8. Hassan, Manal M. et al. "Risk Factors for Pancreatic Cancer: Case-Control Study." The American journal of gastroenterology 102.12 (2007): 2696-2707.

9. Lowenfels AB, Maisonneuve P, Cavallini G, et al. Pancreatitis and the risk of pancreatic cancer. International Pancreatitis Study Group. N Engl J Med 1993;328:1433-7.
10. Warshaw AL, Fernandez-del Castillo C. Pancreatic carcinoma. N Engl J Med 1992;326:455-465.

11. Chari ST, Mohan V, Pitchumoni CS, et al. Risk of pancreatic carcinoma in tropical calcific pancreatitis. Pancreas 1993;9:62-6.

12. Gullo L, Pezzilli R, et al. Diabetes and pancreatic cancer. Pancreas. 2004 May;28(4):451.

13. Fisher WE. Diabetes: Risk factor for the development of pancreatic cancer or manifestation of the disease? World J Surg 2001;25:503-8.

14. Fisher WE, Boros LG, O'Dorisio TM, et al. GI hormonal changes in diabetes influence pancreatic cancer growth. J Surg Res 1995;58:754-8.

15. Fisher WE, Boros LG, Schirmer WJ. Reversal of enhanced pancreatic cancer growth in diabetes by insulin. Surgery 1995;118:453-7.

16. Fisher WE, Muscarella P, Boros LG, et al. Variable effect of streptozotocin-diabetes on the growth of hamster pancreatic cancer $(\mathrm{H} 2 \mathrm{~T})$ in the Syrian hamster and nude mouse. Surgery 1998;123:315- 20.

17. Permert J, Adrian TE, Jacobsson P, et al. Is profound peripheral insulin resistance in patients with pancreatic cancer caused by a tumor-associated factor? Am J Surg 1993;165:61-6.

18. Nakamori S, Ishikawa O, Ohigashi H, et al. Increased blood proinsulin and decreased Cpeptide levels in patients with pancreatic cancer. Hepatogastroenterology 1999;46:1624.

19. Farrow B, Sugiyama Y, Chen A, et al. Inflammatory mechanisms contributing to pancreatic cancer development. Ann Surg 2004;239:763-9.

20. Farrow B, Evers BM. Inflammation and the development of pancreatic cancer. Surg Oncol 2002;10:153-69.

21. Woutersen RA, Visser CJ. In: Yirmiya R, Taylor A, editors. Alcohol and cancer of the 
pancreas. Alcohol, immunity, and cancer. Boca Raton: CRC Press. 1993.

22. Velema JP, Walker AM, Gold EB. Alcohol and pancreatic cancer: Insufficient epidemiologic evidence for a causal relationship. Epidemiol Rev 1986;8:28-41.

23. Silverman DT, Risk Factors for Pancreatic Cancer: A Case-Control Study Based on Direct Interviews. Teratogenesis, Carcinogenesis, and Mutagenesis 21:7-25 (2001).

24. Lowenfels AB, Maisonneuve P, Whitcomb DC, et al. Cigarette smoking as a risk factor for pancreatic cancer in patients with hereditary pancreatitis. JAMA 2001;286: 169-70. 